\title{
Clinico-Pathological Patterns and Survival Outcome of Colorectal Cancer in Young Patients: Western Saudi Arabia Experience
}

\author{
Shereef Ahmed Elsamany ${ }^{1,2 *}$, Abdullah Saeed Alzahrani' ${ }^{1}$, Mervat Mahrous \\ Mohamed $^{3}$,Soha Ali Elmorsy ${ }^{4}$, Jamal Eddin Zekri ${ }^{5,6}$, Ahmed Saleh Al-Shehri ${ }^{7}$, \\ Rasha Mostafa Haggag, ${ }^{1,8}$, Ahmed Abdel-Reheem Alnagar ${ }^{1,8}$, Hani Abdalla El \\ Taani $^{1}$
}

\begin{abstract}
Background: The prognosis of young colorectal cancer (CRC) patients has been addressed by several studies but with contradictory results. The aim of the present study was to evaluate the clinico-pathological features of young Saudi patients with CRC in addition to displaying their survival outcome. Materials and Methods: In this retrospective study, young CRC patients ( $\leq 40$ years) diagnosed between 2007 and 2011 from 4 centres in western Saudi Arabia, were included. Clinico-pathological features, tumor markers, dates of disease relapse and death were collected. Survival parameters were compared with those of older Saudi patients, reported in previous studies. Results: One hundred and sixteen young patients with CRC were identified $(32.2 \%$ rectal, 67.8\% colon). Some $44 \%$ were metastatic while $32.7 \%$ had stage III at diagnosis. Patients with grade 3 tumors made up $29.4 \%$ of the total while $49.5 \%$ had positive lymphovascular invasion (LVI), $56 \%$ had a lymph node $(\mathrm{LN})$ ratio $\geq 0.2$ and $40.2 \%$ were $\mathrm{K}$-ras mutant. Median disease-free survival (DFS) and overall survival (OS) in non-metastatic cases were 22.8 and 49.6 months respectively with better median DFS in K-ras wild compared to mutant patients ( 28.5 vs 20.9 months, $\mathrm{p}=\mathbf{0 . 0 0 5}$ ). In metastatic cases, median OS was 19.5 months. These survival outcomes are inferior compared to those of older Saudi patients reported in prior studies. Conclusions: Young CRC patients present more commonly with advanced stage and a high incidence of adverse prognostic factors such as LVI and high LN ratio. Young CRC patients seem to have worse survival compared to older Saudi patients.
\end{abstract}

Keywords: Young patients - colorectal cancer - clinicopathological - survival - Saudi Arabia

Asian Pac J Cancer Prev, 15 (13), 5239-5243

\section{Introduction}

In Saudi Arabia, CRC incidence, morbidity and related mortality have been steadily increasing over the past twenty years (Ibrahim et al., 2008). There were 904 new cases of CRC accounting for $10.2 \%$ of all newly diagnosed cancer patients in 2008 (Bazarbashi et al., 2008). This cancer ranks first among males and third among female population (male to female ratio of 112:100) with median age at diagnosis of 59 years in males and 57 years in females (Bazarbashi et al., 2008).

In Saudi population, $20.9 \%$ of CRC patients are younger than 45 years of age (Mosli, 2012a). This percentage is similar to that reported in Jordan (20.2\%) (Al-Jaberi et al., 2003), and Egypt (22\%) (Veruttipong et al., 2012). Noteworthy, in western population, the incidence of the disease has increased in the 30-39 years group at an annual rate of $3 \%$ in men and $2 \%$ in women from 1992 to 2005 (Siegel et al., 2009)

Some studies suggest that young CRC patients are diagnosed more frequently in advanced stage (Dozois et al., 2008). A publication based on the SEER database has demonstrated a higher frequency of stage III and IV disease in younger compared to older patients that was highly statistically significant (O'Connell et al., 2004a). Most series have suggested that young adults present

${ }^{1}$ Department of Medical Oncology, Oncology centre, King Abdullah Medical City, ${ }^{4}$ Department of Research, King Abdullah Medical City, ${ }^{3}$ Department of Medical Oncology, King Fahd Hospital, Maddinah, ${ }^{5}$ Department of Medical Oncology, King Faisal Specialist Hospital, Jeddah, ${ }^{6}$ Department of Medicine, Faculty of Medicine, Al-Faisal University, Jeddah, ${ }^{7}$ Department of Medical Oncology, National Guard Hospital, Jeddah, Saudi Arabia, ${ }^{2}$ Department of Medical Oncology, Oncology centre, Faculty of Medicine, Mansoura University, Mansoura, ${ }^{8}$ Department of Medical Oncology, Faculty of Medicine, Zagazig University Hospital, Zagazig, Egypt *For correspondence: samanyshereef@yahoo.com 
with a more aggressive disease (O'Connell et al., 2004b). Tumors are more often poorly differentiated, mucinous or have signet ring histology, features often associated with adverse outcome (Hill et al., 2007; Bleyer et al., 2008).

There have been contradictory reports describing the clinical outcome in young patients with CRC. Some studies suggested that young patients presenting with advanced CRC have a higher risk of long-term mortality compared to older patients (Forbes et al., 2010). An analysis of 20,034 patients in 24 phase III clinical trials, showed that the young CRC patients had 30\% increased risk of death and $28 \%$ increased risk of disease progression compared to middle-aged patients (Lieu, 2013). Genetic and dietary factors were suggested to play a role in this poor outcome (Arafa et al., 2011; Zandonai et al., 2012). In contrast, pooled data from randomized phase III clinical trials showed no difference in relapse free interval in younger versus older patients with a cut-off of 40 years and younger patients had even longer OS (Hubbard et al., 2012).

The aim of the present study is to assess the clinicopathological features of young Saudi patients with CRC in addition to evaluating their survival outcome and to compare this data with other reports from the Saudi population.

\section{Materials and Methods}

\section{Study population and design}

Patients with colorectal cancer $\leq 40$ years at diagnosis who presented to the contributing institutions from May 2007 to January 2011 were included. In this retrospective study involving patients from 4 centres in western Saudi Arabia, young colorectal cancer patients were identified through review of medical records.

Clinico-pathological data was collected including age, gender, site of the primary tumor in addition to the tumor grade, lymphovascular invasion (LVI), perineural invasion (PNI), TNM staging (7th edition), lymph node (LN) ratio and K-RAS status. LN ratio was defined as the number of LNs positive for malignant infiltration divided by the total number of dissected LNs. CEA, CA19-9 levels at time of diagnosis were also checked.

In addition, data of disease relapse and death, if any were collected. Disease free survival (DFS) was assessed in non-metastatic patients while overall survival (OS) was evaluated in metastatic and non-metastatic cases. The impact of different clinico-pathological variables on survival outcome was assessed in metastatic and nonmetastatic patients separately.

\section{Statistical analysis}

SPSS version 21 statistical program was used. Descriptive statistics were performed for all clinical, laboratory and pathological data. The cut off between low and high LN ratio was set at 0.2 for analysis purpose while CEA cut off was set at $50 \mathrm{ng} / \mathrm{ml}$ given that serum CEA elevation greater than 10 times the normal value was found to be correlated with poor prognosis (Webb et al., 1995).

Chi-square test was used to compare these features in metastatic $v s$ non-metastatic patients and in K-RAS wild vs mutant cases. Survival data was presented by Kaplan Meier method where cases with no recorded events (death or relapse) were censored at the date of last contact. Survival analyses were performed separately for metastatic and non-metastatic cases. Within each of the latter groups, comparisons of survival were made based on different variables using the log rank test. Cox regression models for different variables were also constructed separately for metastatic and non-metastatic cases.

Disease free survival (DFS) was defined as the time from date of surgery till the date of documented disease relapse. Overall survival (OS) is defined as the time from date of diagnosis of CRC to the date of death due to any cause. A two-sided alpha was set at 0.05 .

\section{Results}

\section{Clinico-pathological features}

One hundred and sixteen patients diagnosed with CRC at 40 years or younger were identified (63 males, 53 females). The median follow up was 42 months (range 30-70 months). The most frequent age category was 35-40 years while patients $\leq 30$ years were the least frequent $(42.3 \%, 22.4 \%$ respectively). The rectum was the most common site followed by the sigmoid colon $(31.9 \%, 27.5 \%$ respectively). Grade 2 tumors were the most frequently encountered followed by grade $3(58.7 \%$, $29.3 \%$ respectively). Positive LVI was found in about half of the patients $(49.5 \%)$ while only one fourth of the patients had positive PNI (24.4\%). In addition, $40.2 \%$ of patients had K-RAS mutations. Noteworthy, the majority of patients had advanced stage at diagnosis (stage IV: $44.0 \%$, stage III: $32.7 \%$ ).

Table 1 shows the distribution of clinico-pathological variables in metastatic compared to non-metastatic patients. CEA $>50 \mathrm{ng} / \mathrm{ml}$ at diagnosis was more commonly found in metastatic patients $(66.7 \%$ of metastatic cases compared to $25.0 \%$ in non-metastatic cases) $(\mathrm{p}=0.0001)$. Patients having tumors that originated from the rectum or sigmoid colon were more commonly metastatic than those originating from the right or left/transverse colon $(\mathrm{p}=0.03)$. K-RAS mutations were detected more commonly in metastatic patients $(50 \%$ in metastatic $v s$ $32.2 \%$ in non-metastatic cases), however the difference was not statistically significant $(\mathrm{p}=0.07)$. No statistically significant differences were detected in the distribution of other variables between metastatic and non-metastatic patients including age, gender, LVI, PNI, tumor grade, $\mathrm{LN}$ ratio.

Table 2 displays the distribution of different variables in K-RAS wild compared to K-RAS mutant patients. Wild K-RAS status was much more common in tumors originating from the proximal and descending colon. In contrast, K-RAS mutations were more frequently found among sigmoid and rectal tumors $(\mathrm{p}=0.04)$. CEA $>50 \mathrm{ng} /$ $\mathrm{ml}$ was significantly more common among K-RAS mutant patients compared to K-RAS wild patients $(56.3 \%$ vs $32.6 \%$ respectively) $(\mathrm{p}=0.04)$. K-RAS mutant cases had more frequently high $\mathrm{LN}$ ratio and the difference approached statistical significance $(\mathrm{p}=0.06)$. 
Table 1.Patient Characteristics in Metastatic and nonMetastatic Patients

\begin{tabular}{|c|c|c|c|c|}
\hline Characteristics & $\begin{array}{l}\text { Non-metastatic } \\
\qquad(\mathrm{N}=65)\end{array}$ & $\begin{array}{c}\text { Metastatic } \\
(\mathrm{N}=51)\end{array}$ & $\begin{array}{l}\text { Total } \\
(116)\end{array}$ & $\mathrm{p}$ value \\
\hline \multicolumn{5}{|l|}{$\overline{\text { Age }}$} \\
\hline$\leq 30$ & $13(20.0 \%)$ & $13(25.5 \%)$ & 26 & \multirow[t]{4}{*}{0.67} \\
\hline$>30-35$ & $25(38.5 \%)$ & $16(31.4 \%)$ & 41 & \\
\hline$>35-40$ & $27(41.5 \%)$ & $22(43.1 \%)$ & 49 & \\
\hline Total & 65 & 51 & 116 & \\
\hline \multicolumn{5}{|l|}{ Gender-N (\%) } \\
\hline Male & $34(52.3 \%)$ & $29(56.9 \%)$ & 63 & \multirow[t]{3}{*}{0.71} \\
\hline Female & $31(47.7 \%)$ & $22(43.1 \%)$ & 53 & \\
\hline Total & 65 & 51 & 116 & \\
\hline \multicolumn{5}{|l|}{ CEA-N (\%) } \\
\hline$>50 \mathrm{ng} / \mathrm{ml}$ & $11(25 \%)$ & $22(66.7 \%)$ & 33 & \multirow[t]{3}{*}{0.0001} \\
\hline$\leq 50 \mathrm{ng} / \mathrm{ml}$ & $33(75 \%)$ & $11(33.3 \%)$ & 44 & \\
\hline Total & 44 & 33 & 77 & \\
\hline \multicolumn{5}{|l|}{ CA $19-9-\mathrm{N}(\%)$} \\
\hline$\leq 30 \mathrm{U} / \mathrm{ml}$ & $12(52.2 \%)$ & $2(28.6 \%)$ & 14 & \multirow[t]{3}{*}{0.4} \\
\hline$>30 \mathrm{U} / \mathrm{ml}$ & $11(47.8 \%)$ & $5(71.4 \%)$ & 16 & \\
\hline Total & 23 & 7 & 30 & \\
\hline \multicolumn{5}{|l|}{ Grade - N (\%) } \\
\hline G1, & $7(11.7 \%)$ & $6(12.2 \%)$ & 13 & \multirow{4}{*}{0.42} \\
\hline G2 & $32(53.3 \%)$ & $32(65.3 \%)$ & 64 & \\
\hline G3 & $21(35.0 \%)$ & $11(22.5 \%)$ & 32 & \\
\hline Total & 60 & 49 & 109 & \\
\hline \multicolumn{5}{|l|}{$1 \mathrm{LN}$ ratio } \\
\hline$<0.2$ & $29(47.5 \%)$ & $8(34.8 \%)$ & 37 & \multirow[t]{3}{*}{0.33} \\
\hline$\geq 0.2$ & $32(52.5 \%)$ & $15(65.2 \%)$ & 47 & \\
\hline Total & 61 & 23 & 84 & \\
\hline \multicolumn{5}{|l|}{ 2LVI-N (\%) } \\
\hline Yes & $31(56.4 \%)$ & $14(38.9 \%)$ & 45 & \multirow[t]{3}{*}{0.1} \\
\hline No & $24(43.6 \%)$ & $22(61.1 \%)$ & 46 & \\
\hline Total & 55 & 36 & 91 & \\
\hline \multicolumn{5}{|l|}{ 3PNI- N (\%) } \\
\hline Yes & $13(25.0 \%)$ & $8(23.5 \%)$ & 21 & \multirow[t]{3}{*}{0.88} \\
\hline No & $39(75.0 \%)$ & $26(76.5 \%)$ & 65 & \\
\hline Total & 52 & 34 & 86 & \\
\hline \multicolumn{5}{|l|}{ Site- N (\%) } \\
\hline Rightcolon & $13(20.3 \%)$ & $4(7.8 \%)$ & 17 & \multirow[t]{5}{*}{0.03} \\
\hline Left/Transverse & $20(31.3 \%)$ & $9(17.6 \%)$ & 29 & \\
\hline Sigmoid & $16(25.0 \%)$ & $16(31.4 \%)$ & 32 & \\
\hline Rectum & $15(23.4 \%)$ & $22(43.1 \%)$ & 37 & \\
\hline Total & 64 & 51 & 115 & \\
\hline \multicolumn{5}{|l|}{ K-RAS-N (\%) } \\
\hline Wild & $40(67.8 \%)$ & $24(50.0 \%)$ & $64(59.8 \%)$ & \multirow[t]{3}{*}{0.07} \\
\hline Mutant & $19(32.2 \%)$ & $24(50.0 \%)$ & $43(40.2 \%)$ & \\
\hline Total & 59 & 48 & 107 & \\
\hline
\end{tabular}

${ }^{*} \mathrm{LN}$ : lymph node, ${ }^{2} \mathrm{LVI}$ : lymphovascular invasion, ${ }^{3} \mathrm{PNI}$ : perineural invasion

No statistically significant differences were found in the distribution of other variables between wild and mutant K-RAS patients including age, gender, CA19-9, grade, LVI, PNI and TNM-stage.

\section{Survival patterns}

The median OS of non-metastatic patients was 49.6 months (95\% CI 26.7 - 72.4 months) with $43 \%$ 5-year OS compared to 19.5 months median survival (95\% CI 13.125.8 months) and $17 \%$ 5-year OS in metastatic patients (Figure 1). OS was evaluated according to different variables to assess for possible predictors of survival. In metastatic patients, those with grade 3 tumors had worse OS compared to those with grade 1,2 tumors (median OS 11.7 vs 21.1 months respectively) and the difference was of borderline significance $(\mathrm{p}=0.057, \mathrm{HR}=2.1)$. However, no difference in survival could be detected according to other variables. In addition, OS in non-metastatic patients was balanced according to different parameters and no significant differences in survival were detected.
The median DFS in non-metastatic patients was 22.8 months (95\% CI 19.0-26.5) with 28\% 5-year DFS. DFS was assessed according to different parameters to assess for possible predictors of improved DFS. Patients with wild K-RAS had significantly improved DFS compared to K-RAS mutant patients (median DFS: 28.5 vs 20.9 months

Table 2. Patient Characteristics according to K-RAS Status

\begin{tabular}{|c|c|c|c|c|}
\hline Characteristics & $\begin{array}{c}\text { Wild } \\
(\mathrm{N}=64)\end{array}$ & $\begin{array}{l}\text { Mutant } \\
(\mathrm{N}=43)\end{array}$ & $\begin{array}{c}\text { Total } \\
(\mathrm{N}=107)\end{array}$ & $\mathrm{p}$ value \\
\hline \multicolumn{5}{|l|}{ Age } \\
\hline$\leq 30$ & $11(17.2 \%)$ & $13(30.2 \%)$ & 24 & \multirow[t]{4}{*}{0.27} \\
\hline$>30-35$ & $25(39.1 \%)$ & $13(30.2 \%)$ & 38 & \\
\hline$>35-40$ & $28(43.8 \%)$ & $17(39.5 \%)$ & 45 & \\
\hline Total & 64 & 43 & 107 & \\
\hline \multicolumn{5}{|l|}{ Gender -N (\%) } \\
\hline Male & $37(57.8 \%)$ & $21(48.8 \%)$ & 58 & \multirow[t]{3}{*}{0.36} \\
\hline Female & $27(42.2 \%)$ & $22(51.2 \%)$ & 49 & \\
\hline Total & 64 & 43 & 107 & \\
\hline \multicolumn{5}{|l|}{ CEA - N (\%) } \\
\hline$>50 \mathrm{ng} / \mathrm{ml}$ & $14(32.6 \%)$ & $18(56.3 \%)$ & 32 & \multirow[t]{3}{*}{0.04} \\
\hline$\leq 50 \mathrm{ng} / \mathrm{ml}$ & $29(67.4 \%)$ & $14(43.8 \%)$ & 43 & \\
\hline Total & 43 & 32 & 75 & \\
\hline \multicolumn{5}{|l|}{ CA $19-9-\mathrm{N}(\%)$} \\
\hline$>30 \mathrm{U} / \mathrm{ml}$ & $8(47.1 \%)$ & $8(61.5 \%)$ & 16 & \multirow[t]{3}{*}{0.43} \\
\hline$\leq 30 \mathrm{U} / \mathrm{ml}$ & $9(52.9 \%)$ & $5(38.5 \%)$ & 14 & \\
\hline Total & 17 & 13 & 30 & \\
\hline \multicolumn{5}{|l|}{ Grade-N (\%) } \\
\hline G1 & $9(14.1 \%)$ & $4(9.3 \%)$ & 13 & \multirow[t]{4}{*}{0.19} \\
\hline G2 & $40(62.5 \%)$ & $22(51.2 \%)$ & 62 & \\
\hline G3 & $15(23.4 \%)$ & $17(39.5 \%)$ & 32 & \\
\hline Total & 64 & 43 & 107 & \\
\hline \multicolumn{5}{|l|}{${ }^{1} \mathrm{LVI}-\mathrm{N}(\%)$} \\
\hline Yes & $23(43.4 \%)$ & $22(59.0 \%)$ & 45 & \multirow[t]{3}{*}{0.13} \\
\hline No & $30(56.6 \%)$ & $15(40.5 \%)$ & 45 & \\
\hline Total & 53 & 37 & 90 & \\
\hline \multicolumn{5}{|l|}{${ }^{2} \mathrm{PNI}-\mathrm{N}(\%)$} \\
\hline Yes & $12(24.0 \%)$ & $9(25.0 \%)$ & 21 & \multirow[t]{3}{*}{0.91} \\
\hline No & $38(76.0 \%)$ & $27(75.0 \%)$ & 65 & \\
\hline Total & 50 & 36 & 86 & \\
\hline \multicolumn{5}{|l|}{ Site- N (\%) } \\
\hline Right colon & $13(20.6)$ & $3(7.0 \%)$ & 16 & \multirow[t]{5}{*}{0.04} \\
\hline Left/Transverse & $18(28.6 \%)$ & $8(18.6 \%)$ & 26 & \\
\hline Sigmoid & $13(20.6 \%)$ & $18(41.9 \%)$ & 31 & \\
\hline Rectum & $19(30.2 \%)$ & $14(32.6 \%)$ & 33 & \\
\hline Total & 63 & 43 & 106 & \\
\hline \multicolumn{5}{|l|}{ T-stage } \\
\hline $\mathrm{T} 1$ & $6(9.4 \%)$ & $5(11.6 \%)$ & 11 & 0.63 \\
\hline T2 & $11(17.2 \%)$ & $3(7.0 \%)$ & 14 & \\
\hline $\mathrm{T} 3$ & $29(45.3 \%)$ & $23(53.5 \%)$ & 52 & \\
\hline $\mathrm{T} 4$ & $16(25.0 \%)$ & $11(25.6 \%)$ & 27 & \\
\hline $\mathrm{TX}$ & $2(3.1 \%)$ & $1(2.3 \%)$ & 3 & \\
\hline Total & 64 & 43 & 107 & \\
\hline N-Stage & & & & \\
\hline No & $21(32.8 \%)$ & $7(16.3 \%)$ & 28 & 0.09 \\
\hline N1 & $20(31.3 \%)$ & $11(25.6 \%)$ & 31 & \\
\hline $\mathrm{N} 2$ & $12(18.8 \%)$ & $16(37.2 \%)$ & 28 & \\
\hline NX & $11(17.2 \%)$ & $9(20.9 \%)$ & 20 & \\
\hline Total & 64 & 43 & 107 & \\
\hline $3 \mathrm{LN}$ ratio & & & & \\
\hline$<0.2$ & $25(53.2 \%)$ & $9(31.0 \%)$ & 34 & 0.06 \\
\hline$\geq 0.2$ & $22(46.8 \%)$ & $20(69.0 \%)$ & 42 & \\
\hline Total & 47 & 29 & 76 & \\
\hline Stage & & & & \\
\hline I & $5(7.9 \%)$ & 0 & 5 & 0.28 \\
\hline II & $14(21.9 \%)$ & $7(16.3 \%)$ & 21 & \\
\hline III & $19(29.7 \%)$ & $12(27.9 \%)$ & 31 & \\
\hline IV & $26(20.6 \%)$ & $24(55.8 \%)$ & 50 & \\
\hline Total & 64 & 43 & 107 & \\
\hline
\end{tabular}

${ }^{* 1}$ LVI: lymphovascular invasion, ${ }^{2} \mathrm{PNI}$ : perineural invasion, ${ }^{3} \mathrm{LN}$ : lymph node 


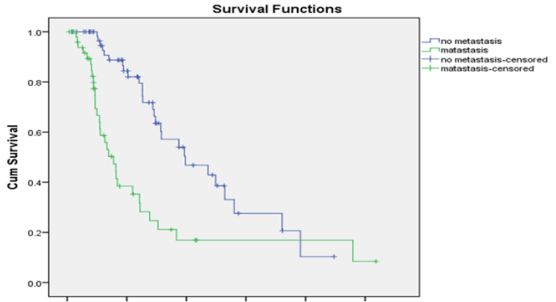

Figure 1. Overall Survival (OS) in Metastatic and Non-Metastatic Patients
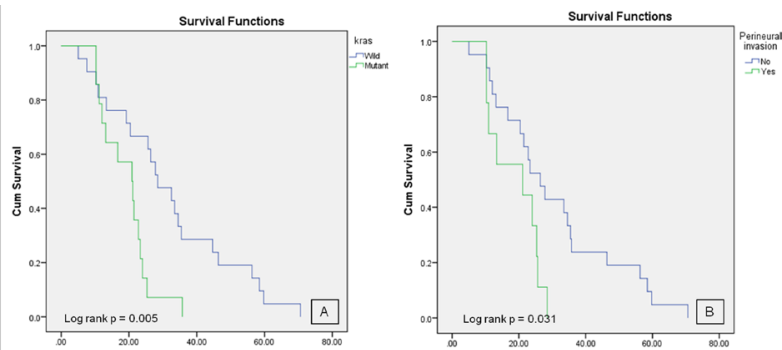

Figure 2. A) Disease Free Survival in K-RAS wild Compared to K-RAS mutant Patients. B) Disease free Survival in Patients with and without Perineural invasion

Table 3. Comparison of Disease Free Survival (DFS) in Non-Metastatic Patients According to Different Variables

\begin{tabular}{|c|c|c|c|c|}
\hline Characteristics & & $\begin{array}{l}\text { Median DFS in } \\
\text { months }(95 \% \mathrm{CI})\end{array}$ & $\begin{array}{c}\mathrm{HR} \\
(95 \% \mathrm{CI})\end{array}$ & $\mathrm{p}$ value \\
\hline All & & $22.8(19.0-26.5)$ & - & - \\
\hline \multirow[t]{2}{*}{ Age } & $\leq 35$ & $24.0(20.2-28.7)$ & 0.81 & 0.56 \\
\hline & $>35$ & 20.4(13.9-26.9) & $(0.41-1.63)$ & \\
\hline \multirow[t]{2}{*}{ Gender-N (\%) } & Male & $25.6(20.3-30.8)$ & 0.62 & 0.18 \\
\hline & Female & $20.9(19.5-22.3)$ & $(0.3-1.26)$ & \\
\hline \multirow[t]{2}{*}{ CEA-N (\%) } & $\leq 50 \mathrm{ng} / \mathrm{ml}$ & $20.4(10.2-30.6)$ & 1.19 & 0.7 \\
\hline & $>50 \mathrm{ng} / \mathrm{ml}$ & $24.0(20.4-27.6)$ & $(0.49-2.86)$ & \\
\hline \multirow[t]{2}{*}{ Stage } & Stage I, II & $26.4(19.0-33.8)$ & 1.38 & 0.37 \\
\hline & Stage III & $21.5(18.7-24.3)$ & $(0.68-2.8)$ & \\
\hline \multirow[t]{2}{*}{$\mathrm{N}$-stage } & No & $27.8(24.6-31.0)$ & 1.8 & 0.13 \\
\hline & $\mathrm{N} 1, \mathrm{~N} 2$ & $21.5(18.5-24.6)$ & $(0.84-3.83)$ & \\
\hline \multirow[t]{2}{*}{ Grade-N (\%) } & $\mathrm{G} 1, \mathrm{G} 2$ & $23.3(16.3-30.3)$ & 1.3 & 0.5 \\
\hline & G3 & $21.1(11.7-30.5)$ & $(0.64-2.52)$ & \\
\hline \multirow[t]{2}{*}{$1 \mathrm{LN}$ ratio } & $<0.2$ & $27.8(21.8-33.8)$ & 1.8 & 0.09 \\
\hline & $\geq 0.2$ & $20.9(14.3-27.5)$ & $(0.9-3.8)$ & \\
\hline \multirow[t]{2}{*}{ 2LVI-N (\%) } & No & $23.3(9.2-37.4)$ & 1.04 & 0.9 \\
\hline & Yes & $22.8(18.5-27.0)$ & $(0.5-2.2)$ & \\
\hline \multirow[t]{2}{*}{ 3PNI- N (\%) } & No & 26.4(18.9-33.9) & 2.5 & 0.03 \\
\hline & Yes & $21.1(0.00-43.9)$ & $(1.05-6.17)$ & \\
\hline \multirow[t]{2}{*}{ Site-N (\%) } & Colon & $24.0(19.5-28.5)$ & 1.7 & 0.23 \\
\hline & Rectum & $10.9(0.0-24.4)$ & $(0.7-4.24)$ & \\
\hline \multirow[t]{2}{*}{ K-RAS-N (\%) } & wild & $28.5(19.3-37.6)$ & 2.9 & 0.005 \\
\hline & mutant & $20.9(12.8-29.0)$ & $(1.34-6.44)$ & \\
\hline
\end{tabular}

${ }^{* 1} \mathrm{LN}$ : lymph node, ${ }^{2} \mathrm{LVI}$ : lymphovascular invasion, ${ }^{3} \mathrm{PNI}$ : perineural invasion

respectively, $\mathrm{p}=0.005, \mathrm{HR}=2.9$ ) (Table 3 , figure 2A). Furthermore, patients with negative PNI had significantly better DFS compared to those with positive PNI (median DFS: 26.4 vs 21.1 months respectively, $\mathrm{p}=0.03, \mathrm{HR}=2.5$ ) (Table 3, figure 2B). However, no difference in DFS could be detected according to other variables (Table 3)

\section{Discussion}

In this retrospective study, we evaluated the clinicopathological features and survival patterns of young CRC patients from four oncology centres in western Saudi Arabia. To our knowledge, this is the largest study that addressed young CRC patients in Saudi Arabia.

Some important findings are to be emphasized. The rectum was the most common site followed by the sigmoid colon. The majority of patients presented with advanced stage and several adverse prognostic features were detected frequently such as high LN ratio, positive LVI and grade III tumors. Data from several Saudi studies displayed more common distribution of CRC in older patients in the rectum followed by sigmoid colon (Aljebreen, 2007; Sibiani et al., 2011; Mosli and Alahwal, 2012b). In contrast, another Saudi study reported that right sided tumors were the most common among young CRC patients (Guraya and Eltinay, 2006).

The stage distribution reported by Saudi cancer registry 2008 (stage III $38.8 \%$, stage IV 29.2\%) (Bazarbashi et al., 2008) was similar to that displayed in our study. Noteworthy, advanced stages (stages III and IV) were more frequent in older compared to younger Saudi patients in pooled data from Saudi cancer registry between 2001 and 2006 (Mosli, Al-Ahwal 2012a). Therefore, in our study, the predominant presentation of young CRC patients (diagnosed from 2007-2011) with advanced stages may represent a change in the pattern of the disease in this age group in the recent years.

Compared to our study, lower frequencies of adverse prognostic factors were reported in older Saudi CRC patients (Elsamany et al., 2013). In contrast, K-RAS mutation rate found in our study is comparable to that reported by another multicentre study conducted in western Saudi Arabia (40.2\% vs $40.8 \%$ respectively) (Zekri et al., 2013). In our study, K-RAS mutant patients had more frequently high CEA levels and high $\mathrm{LN}$ ratio. In addition, K-RAS mutations were more common among metastatic patients. Similar findings were reported by Zekri et al., 2013 who displayed that K-RAS mutations are associated with advanced stage and higher CEA at presentation. Noteworthy, the same authors showed better relapse free survival in wild compared to mutant K-RAS patients which is to similar to the results of our study.

Survival outcome of CRC patients in Saudi Arabia was addressed by few studies. However, the survival outcome of young patients in the present study is worse than that reported in older Saudi patients. In one study, median DFS of older Saudi CRC patients was 31.3 (Elsamany et al., 2013) (8.5 months greater than survival outcome in our study). Furthermore, in Saudi patients diagnosed from 1994 to 2004 , the five-year OS was $63.3 \%$ for patients with localized disease, $50.2 \%$ for those with regional disease, and $14.7 \%$ for patients with metastases (Al-Ahwal et al., 2013). Similarly, in a Chinese study, patients younger than 30 years tend to present with advanced stages and they had worse survival than older patients (5- and 10-year OS were $33.9 \%$ and $26.1 \%$, respectively in the younger group compared to $60.1 \%$ and $52.2 \%$, respectively in the older group) (Fu et al., 2013).

However, our study has some limitations. Some patients had missing data and dates of progression were available for only 16 out of 51 metastatic patients which prevented adequate estimation of PFS. Larger number 
of patients is needed for more accurate analysis of the impact of different variables on the survival outcome of young patients. In addition, our study included patients from western Saudi Arabia only which may not reflect the features and survival outcome of young CRC patients in the whole country.

In conclusion, young Saudi CRC patients presented with advanced stage at diagnosis with high frequency of adverse prognostic factors such as LVI and high LN ratio. K-RAS mutations had similar incidence to that reported in older patients and it was associated with higher CEA at presentation and worse DFS. Given the limitations of comparison across different studies, young CRC patients seem to have worse survival compared to older Saudi patients. This data raises the need for early diagnosis and proper treatment strategies for young patients to improve their survival outcome.

\section{Acknowledgements}

The authors would like to thank Dr. Mian Usman Farooq for his technical support in the preparation of the figures of the manuscript.

\section{References}

Al-Ahwal MS, Shafik YH, Al-Ahwal HM (2013). First national survival data for colorectal cancer among Saudis between 1994 and 2004: what's next? BMC Public Health, 13, 73.

Al-Jaberi TM, Yaghan RJ, El-Heis HA (2003). Colorectal cancer in young patients under 40 years of age. Comparison with old patients in a well defined Jordanian population. Saudi Med J, 24, 871-4.

Aljebreen A (2007). Clinico-pathological patterns of colorectal cancer in Saudi Arabia: younger with an advanced stage presentation. Saudi J Gastroenterol, 13, 84-7.

Arafa MA, Waly MI, Jriesat S, Al Khafajei A, Sallam S (2011). Dietary and lifestyle characteristics of colorectal cancer in Jordan: a case-control study. Asian Pac J Cancer Prev, 12, 1931-6.

Bazarbashi S,Al-Zahrani A, Al-Eid HS (2008). Cancer Incidence Report. National Cancer Registry, Ministry of Health, Kingdom of Saudi Arabia.

Bleyer A, Barr R, Hayes-Lattin B, et al (2008). The distinctive biology of cancer in adolescents and young adults. Nat Rev Cancer, 8, 288-98.

Dozois EJ, Boardman LA, Suwanthanma W, et al (2008). Young-onset colorectal cancer in patients with no known genetic predisposition: can we increase early recognition and improve outcome? Medicine, 87, 259-63.

Elsamany S, Alzahrani A, Alkashif A, et al (2013). Impact of timing of adjuvant chemotherapy on prognosis of colon cancer patients. ECC, abstract, 2249.

Forbes S, Sutradhar R, Paszat, et al (2010). Long-term survival in young adults with colorectal cancer: a population-based study. Dis Colon Rectum, 53, 973-8.

Fu JF, Huang YQ, Yang J, et al (2013). Clinical characteristics and prognosis of young patients with colorectal cancer in Eastern China. World J Gastroenterol, 19, 8078-84.

Guraya SY, Eltinay OE (2006). Higher prevalence in young population and rightward shift of colorectal carcinoma. Saudi Med J, 27, 1391-3.

Hill DA, Furman WL, Billups CA, et al (2007). Colorectal carcinoma in childhood and adolescence: a clinico- pathologic review. J Clin Oncol, 25, 5808-14.

Hubbard J, Thomas DM, Yothers G, et al (2012). Benefits and adverse events in younger versus older patients receiving adjuvant chemotherapy for colon cancer: findings from the Adjuvant Colon Cancer Endpoints data set. J Clin Oncol, 30, 2334-9.

Ibrahim EM, Zeeneldin AA, El-Khodary TR, Al-Gahmi AM, Bin Sadiq BM (2008). Past, present and future of colorectal cancer in the Kingdom of Saudi Arabia. Saudi J Gastroenterol, 14, 178-82.

Lieu C (2013). The impact of young age on survival in patients with metastatic colorectal cancer: analysis from the ARCAD Clinical Trials Program. ECC, 2158.

Mosli MH, Al-Ahwal MS (2012). Colorectal cancer in the Kingdom of Saudi Arabia: need for screening. Asian Pac J Cancer Prev, 13, 3809-13.

Mosli MH, Al-Ahwal MS. (2012). Does the increasing trend of colorectal cancer incidence in Jeddah reflect a rise in the Kingdom of Saudi Arabia? Asian Pac J Cancer Prev, 13, 6285-8.

O'Connell JB, Maggard MA, Liu JH, et al (2004a). Do young colon cancer patients have worse outcomes? World J Surg, 28, 558-62.

O'Connell JB, Maggard MA, Livingston EH, et al (2004). Colorectal cancer in the young. Am J Surg, 187, 343-489.

Sibiani A, Shaheen M, Fallatah HI, et al (2011). Colorectal cancer in Saudi Arabia, King Abdul Aziz University Hospital: a five year experience. J Med Medical Sci, 2, 1126-30.

Siegel RL, Jemal A, Ward EM (2009). Increase in incidence of colorectal cancer among young men and women in the United States. Cancer Epidemiol Biomarkers Prev, 18, 1695-8.

Veruttipong D, Soliman AS, Gilbert SF, et al (2012). Age distribution, polyps and rectal cancer in the Egyptian population-based cancer registry. World J Gastroenterol, 18, 3997-4003.

Webb A, Scott-Mackie P, Cunningham D, et al (1995). The prognostic value of CEA, beta HCG, AFP, CA125, CA199 and C-erb B-2, beta HCG immunohistochemistry in advanced colorectal cancer. Ann Oncol, 6, 581-7.

Zandonai AP, Sonobe HM, Sawada NO (2012). The dietary risk factors for colorectal cancer related to meat consumption. Rev Esc Enferm USP, 46, 234-9.

Zekri J, Al-Shehri A, Mahrous M, et al (2013). K-ras status in colorectal cancer tumors from 292 Saudi patients: frequency, clinico-pathological association and clinical outcome. ECC, 2436. 